\title{
Radiation-induced anaplastic astrocytoma following treatment of medulloblastoma
}

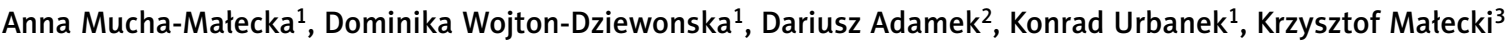 \\ ${ }^{1}$ Clinic of Oncology, Centre of Oncology - Maria Skłodowska-Curie Institute, Cracow, ${ }^{2}$ Department of Pathology, Jagiellonian \\ University Medical College, Cracow, ${ }^{3}$ Department of Radiotherapy for Children and Adults, University Children's Hospital of Cracow, \\ Poland
}

\begin{abstract}
We hereby report a case of a 10-year-old girl in whom neurosurgery was performed for cerebellar vermis medulloblastoma in April 2000. After resection the patient underwent chemotherapy followed by radiotherapy, receiving 53.07 Gy to posterior fossa and 35.07 Gy to the rest of the craniospinal axis. In 2012, she was diagnosed with anaplastic astrocytoma, which was located within the high-dose region. Surgical resection of the tumour was performed. Postoperatively, the patient received radiation therapy (50.4 Gy) with concurrent temozolomide, followed by 6 cycles of adjuvant temozolomide. Five years after the diagnosis of anaplastic astrocytoma, the patient remains asymptomatic.
\end{abstract}

Key words: medulloblastoma, anaplastic astrocytoma, radiation-induced tumour, chemoradiotherapy, reirradiation.

\section{Introduction}

In 1945, at the Memorial Hospital for Cancer and Allied Diseases (nowadays called Memorial Sloan-Kettering Cancer Center), Bradley Coley amputated the lower leg of a 22-year-old man diagnosed with tibial sarcoma. Eight years earlier the patient had been treated with radium because of fibrous dysplasia found radiologically. The dose delivered to the bone was 15.5 Gy [4]. Three years later, in the publication coming from the same institution, Cahan et al. described 11 cases of bone sarcomas (located in the ribs, sternum and clavicle), which occurred in patients irradiated postoperatively for breast cancer. The authors referred to them as second radiation-induced cancer - SRIC and pointed out four essential criteria for their diagnosis: previous irradi- ation, latency period of several years, location of the neoplasm within the irradiated area, and histological proof of malignancy [5]. Until now, the dose needed to initiate carcinogenesis has not been established unequivocally. The results of meta-analyses including over 3000 patients diagnosed with SRIC revealed a linear correlation between the total radiation dose and the frequency of malignancies. The majority of SRIC were diagnosed in the proximity of tissues, which had received doses of 5 to $50 \mathrm{~Gy}[3,33]$.

Postoperative radiation therapy is an integral part of combined treatment of central nervous system tumours. Improving treatment results lead to prolongation of survival, which thus results in an increasing number of secondary brain malignancies. Malignant gliomas (radiation-induced malig- 
nant gliomas - RIMG) comprise more than a half of these neoplasms. The medium latency period varies between 9 and 19 years according to the literature $[6,9,23,26,32]$. We describe a case of secondary anaplastic astrocytoma which occurred 10 years after cerebro-spinal irradiation performed because of cerebellar medulloblastoma in a 10-year-old child.

\section{Case report}

In April 2000, a ten-year-old girl was admitted to the Surgery Department of the Children's University Hospital in Cracow, presenting with a history of 2 months of intensifying headaches in the occipital region, nausea, vomiting and nystagmus. Diagnostic computed tomography (CT) and magnetic resonance imaging (MRI) visualised a tumour of the cerebellar vermis with a diameter of $8 \mathrm{~cm}$. The tumour was excised totally with suboccipital craniectomy on 20 April 2000. The histological examination revealed a highly cellular tumour formed by small, uniform cells with only thin rims of cytoplasm, exceptionally rarely creating rosette-like structures but mostly crowded in compact featureless areas (Fig. 1).

Focally some glial fibrillary acidic protein (GFAP) and synaptophysin immunopositivity was observed. As a result, the diagnosis of medulloblastoma - "classical" variant was established. Cerebrospinal fluid was free from neoplastic cells. The patient received 4 cycles of chemotherapy (SIOP - vincristine, etoposide, cyclofosfamide). Systemic treatment ended on 21 August 2000. From 6 September to 20 October 2000 , the patient received adjuvant irradiation. At the first step, a dose of $35.07 \mathrm{~Gy}$ in 21 fractions to the neuraxis was given. Subsequently, additional $18 \mathrm{~Gy}$ in 10 fractions to the posterior cranial fossa were given, resulting in the total dose of 53.07 Gy in this area. In July 2012, 12 years after the diagnosis of cerebellar medulloblastoma, at the age of 22, the patient was admitted to an emergency department because of an onset of seizures. MRI was performed and showed a tumour measuring $27 \times 22 \times 19 \mathrm{~mm}$, located at the border of the left parietal and occipital lobe, and characterized with malignant features including heterogeneity of enhancement, digitate oedema, and mass effect (Fig. 2).

The patient was admitted to the Neurosurgery Department of the University Hospital in Cracow, where on 18 July 2012, a macroscopic resection of the tumour was performed. The histopathological

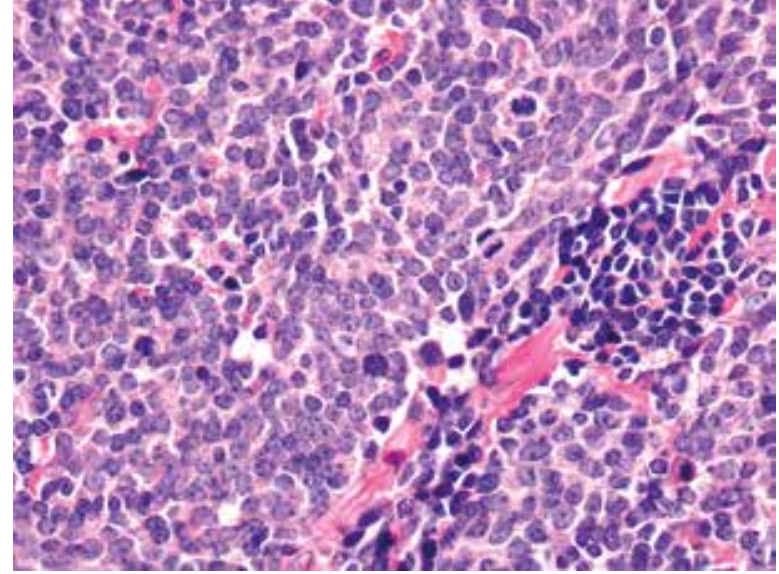

Fig. 1. Medulloblastoma WHO IV (primary tumour). Typical features of a "classic" variant of medulloblastoma. The tumour consists of relatively uniform small anaplastic cells with a high mitotic ratio ( 2 mitoses are seen in the picture), here not forming any particular patterns (like rosettes). Haematoxylin-eosin.

examination revealed an anaplastic tumour of astrocytic type (immunopositivity to GFAP). Tumour cells were mostly of small or medium size, polymorphic and relatively loosely scattered, but somewhat more densely aggregated around numerous vessels, however, not in a "radiating", rosette-like arrangement (Fig. 3A). Immunohistochemistry using a mouse monoclonal antibody targeting the IDH1 R132H mutation has given a negative result.

There were numerous mitoses and conspicuously high Ki67 labelling index of $20 \%$ was noted (Fig. 3B). Some scattered features of cell necrosis could be seen though without formation of palisades. Consequently, a diagnosis of anaplastic astrocytoma WHO III was adopted. From 10 September to 23 October 2012 at the Centre of Oncology in Cracow, adjuvant chemoradiotherapy was performed. The patient was treated with a dose of 50.4 Gy in 28 fractions with concurrent temozolomide. Subsequently she received 6 cycles of adjuvant temozolomide. At present, 5 years after the diagnosis of anaplastic astrocytoma, the patient remains asymptomatic in both clinical examination and imaging.

\section{Discussion}

Radiotherapy is an undisputed element of combined treatment of neoplasms located within the central nervous system. It is applied mainly in high- 

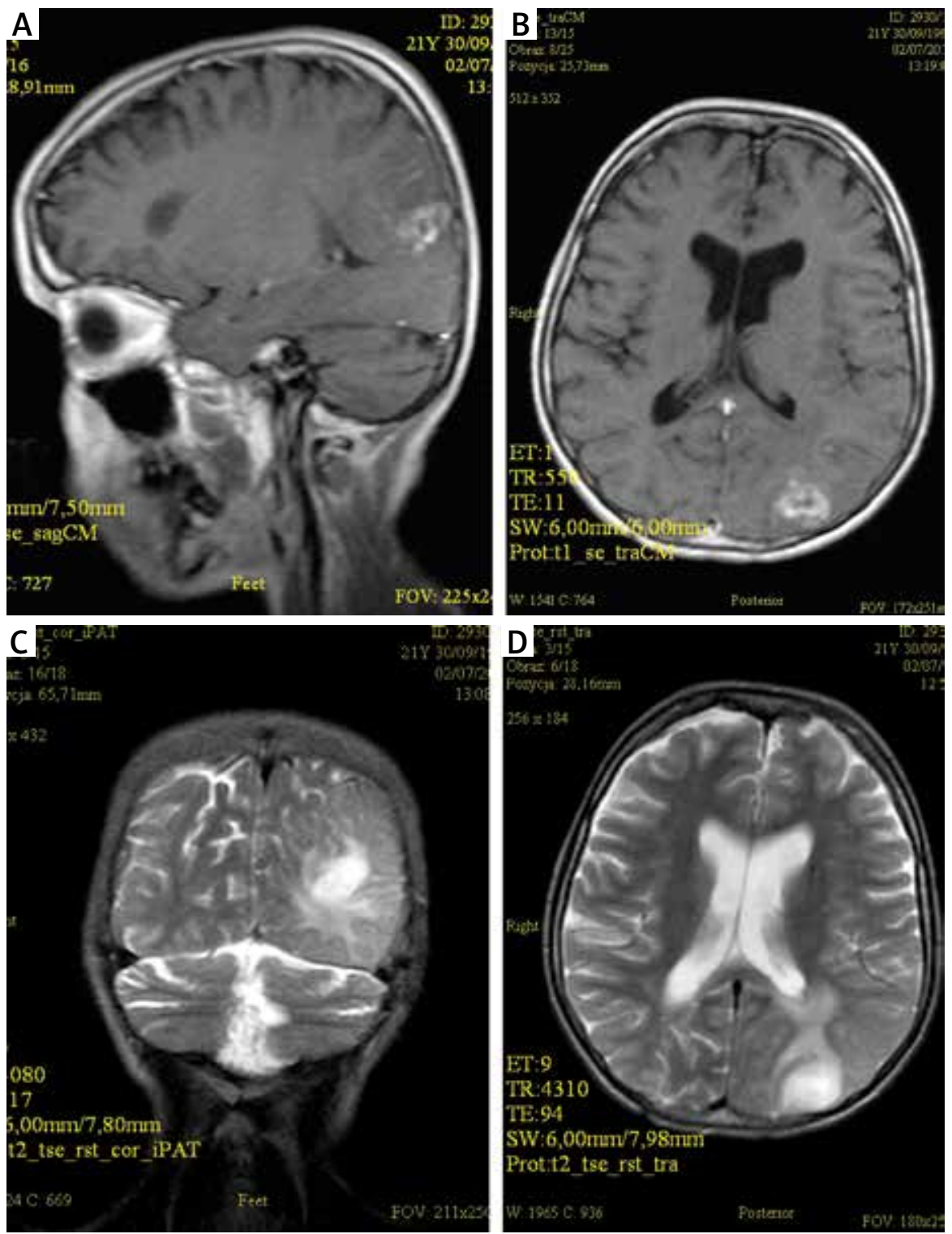

Fig. 2. T1-weighted contrast-enhanced axial and sagittal images showing heterogeneously enhancing tumour at the border of the left parietal and occipital lobe (A, B). T2-weighted image demonstrates the same lesion with digitate oedema and mass effect (C, D).

grade gliomas in adult patients and germinal tumours in children. Radiation therapy, like other methods of oncological treatment, is associated with early and late adverse effects. A lot of data have been collected on the most serious late complication, which is radionecrosis. Over the last decade, lots of reports regarding radiation-induced brain tumours have been published. The occurrence of secondary brain tumours depends on both institutions' and authors' experience. According to Paulino et al., a cumulative risk of secondary glioma is $1.7 \%$ at 10 years, rising to $2.7 \%$ at 15 years [23]. For over $70 \%$ of patients after neuraxis irradiation, who are diagnosed with a secondary tumour, the latency period does not exceed 10 years; however, Hamasaki describes a case, in which the latency period was 35 years $[9,12,19]$. Kamide et al. report a case of a 5 -year-old patient diagnosed with medulloblastoma, treated with surgery for high-grade glioma and meningioma after 29 years. Both lesions were located in the cerebellum, 

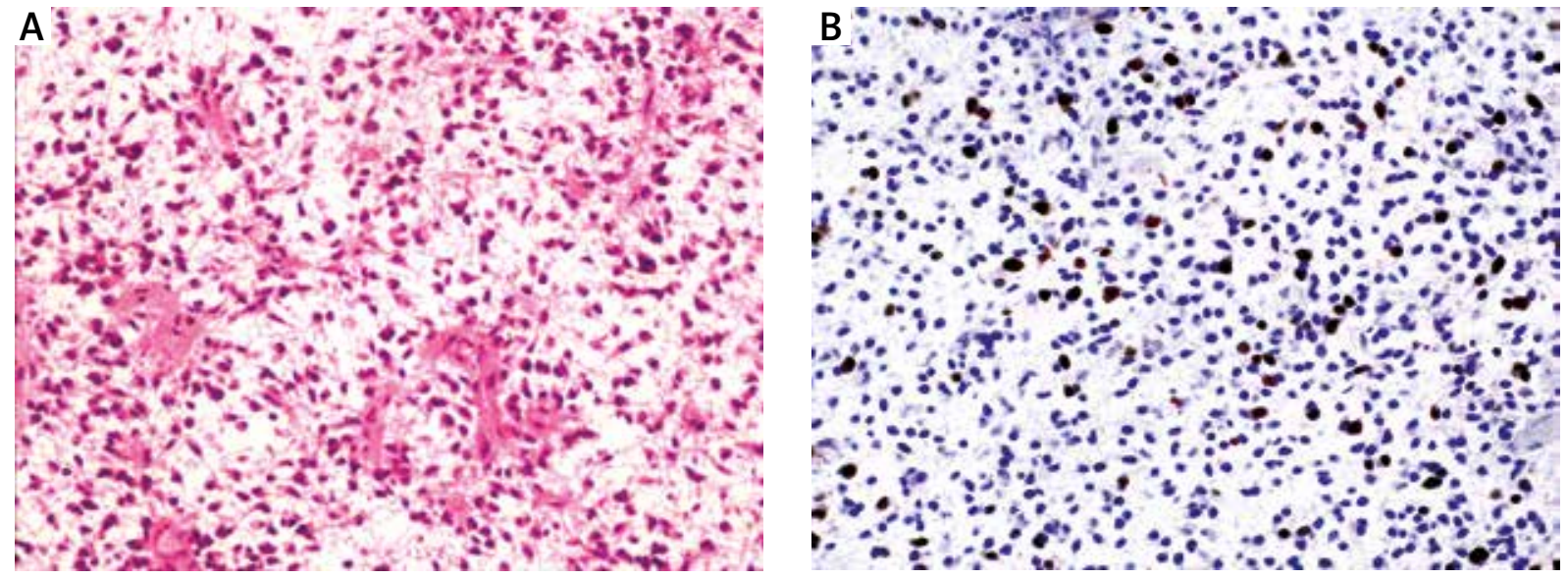

Fig. 3. Secondary tumour diagnosed as anaplastic astrocytoma WHO III. The tumour shows moderate cellularity and quite conspicuous perivascular arrangement of tumour cells (haematoxylin-eosin) (A) and noticeable mitotic activity with a high Ki67 labelling index of 20\% (immunohistochemistry) (B).

thus in the high-dose region [14]. According to the literature, RIMG occur in the areas irradiated with a minimum dose of 30 Gy $[10,17,25,34]$. Table I presents cases of radiation-induced gliomas following treatment of medulloblastoma.

Van Calenbergh et al. define basic criteria of radiation-induced brain tumour: different histopathological features (not only higher grade), location in the irradiated area, latency period of several years (a minimum interval has not been determined yet), excluding tumours in patients with syndromes known to present with multiple neoplasms (e.g. neurofibromatoses) [30]. Our case meets all these criteria: primary neoplasm - medulloblastoma, the secondary one - anaplastic astrocytoma (the above-described astrocytoma apparently shows no IDH-1R132H mutation, at least tested by immunohistochemistry), development in the region irradiated with a dose of 35.07 Gy and latency period of 10 years. Although in our case, glioma was ultimately diagnosed as grade III astrocytoma, we are aware that to some extent its morphology may resemble pilomyxoid astrocytoma (which is grade II). However, this resemblance is only due to loose cellularity of the tumour and oedema. The tumour was devoid of any true "myxoid" features and although tumour cells were denser around vessels, no typical "radiating" rosette-like arrangements around vessels (quite characteristic in pilomyxoid astrocytoma) were noted and also neuroimaging features were not typical for pilomyxoid astrocytoma. Secondary gliomas may have different morphology and show a broad spectrum regarding their aggressiveness, including a high as well as a low grade and the relation between histopathology and clinical behaviour in secondary gliomas differs from what is observed in primary tumours $[13,16,35]$. In our case frequent mitoses and especially high Ki67 labelling index of 20\% (Fig. 3B) pointed out to a rather truly aggressive course and this led to diagnosis of grade III astrocytoma. What additionally corroborated with neuroimaging features of grade III tumour was heterogeneity of enhancement, digitate oedema, and mass effect.

Standard treatment of primary high-grade gliomas consists of postoperative radiotherapy to a total dose of $60 \mathrm{~Gy}$ in 30 fractions given concurrently with temozolomide and followed by 6 cycles of temozolomide alone. Repeated irradiation of previously irradiated area seems controversial, thus in many institutions it is not performed [22]. The treatment of RIMG should take into account the dose delivered during the first radiotherapy, the irradiated volume and the latency period. The decision concerning repeated radiotherapy should be made taking these variables into account. Keeping in mind that medium latency period between the first and the repeated treatment is 9 years and relying on previous experience, we estimate that delivering the dose of 50-55 Gy concurrently with chemotherapy is safe $[1,2,8,28,31]$.

Paulino et al. reviewed the literature from 1960 to 2005, finding 92 patients diagnosed with RIMG. The majority of patients (73\%) were under 19 years old 
Table I. Radiation-induced gliomas following treatment of medulloblastoma

\begin{tabular}{|c|c|c|c|c|c|c|c|}
\hline No. & Author & $\begin{array}{l}\text { Age [years]/ } \\
\text { Sex }\end{array}$ & $\begin{array}{l}\text { Total dose } \\
\text { (brain) [Gy] }\end{array}$ & $\begin{array}{c}\text { Total dose } \\
\text { (posterior cranial } \\
\text { fossa) [Gy] }\end{array}$ & Chemotherapy & $\begin{array}{l}\text { Latency } \\
\text { period } \\
\text { [years] }\end{array}$ & $\begin{array}{l}\text { Radiation-induced } \\
\text { high-grade glioma }\end{array}$ \\
\hline 1 & Kleriga [15] (1978) & $0.8 / \mathrm{M}$ & 50 & - & & 11 & $\begin{array}{l}\text { High-grade glioma, } \\
\text { cerebellum }\end{array}$ \\
\hline 2 & Pearl [22] (1980) & $5 / M$ & 30 & +10 & & 13 & GBM, parietal lobe \\
\hline 3 & Cohen [7] (1981) & $4 / K$ & 35 & +10 & & 14 & $\begin{array}{l}\text { High-grade glioma, } \\
\text { frontal lobe }\end{array}$ \\
\hline 4 & $\begin{array}{c}\text { Schmidbauer [27] } \\
\text { (1987) }\end{array}$ & $13 / M$ & 60 & - & $\begin{array}{l}\text { Vincristine } \\
\text { Lomustine }\end{array}$ & 6 & $\begin{array}{c}\text { GBM, } \\
\text { cerebellum }\end{array}$ \\
\hline 5 & $\begin{array}{c}\text { Safneck [24] } \\
(1992)\end{array}$ & $2 / M$ & 44 & +10 & & 11 & $\begin{array}{c}\text { AA, } \\
\text { optic nerve }\end{array}$ \\
\hline 6 & Osumi [20] (1994) & $14 / K$ & 50 & - & $\begin{array}{l}\text { Vincristine } \\
\text { Lomustine }\end{array}$ & 9 & $\begin{array}{l}\text { High-grade glioma, } \\
\text { cerebellum }\end{array}$ \\
\hline 7 & Grabb [11] (1996) & $39 / K$ & 42.5 & +11.9 & & 17 & $\begin{array}{c}\text { AA, cervical spinal } \\
\text { cord }\end{array}$ \\
\hline 8 & Furuta [9] (1998) & $8 / M$ & 40 & +15 & & 15 & $\begin{array}{l}\text { High-grade glioma, } \\
\text { cerebellum }\end{array}$ \\
\hline 9 & $\begin{array}{c}\text { Van Calenbergh } \\
\text { [30] (1999) }\end{array}$ & $2 / M$ & 40 & +10 & & 15 & $\begin{array}{l}\text { AA, parieto-occipital } \\
\text { region }\end{array}$ \\
\hline 10 & $\begin{array}{c}\text { Strojan [29] } \\
(2000)\end{array}$ & $10 / K$ & 30 & +29.5 & & 34 & $\begin{array}{l}\text { Pilocytic glioma, } \\
\text { cerebellar vermis }\end{array}$ \\
\hline 11 & $\begin{array}{l}\text { Nakamizo [19] } \\
\text { (2001) }\end{array}$ & $11 / M$ & 30 & +24 & $\begin{array}{l}\text { Methotrexate } \\
\text { Cytarabine }\end{array}$ & 9 & $\begin{array}{l}\text { High-grade glioma, } \\
\text { cerebellum }\end{array}$ \\
\hline 12 & $\begin{array}{l}\text { Nakamizo [19] } \\
(2001)\end{array}$ & 18/K & 30 & +20 & & 9 & $\begin{array}{l}\text { High-grade glioma, } \\
\text { cerebellum }\end{array}$ \\
\hline 13 & Malde [18] (2003) & $13 / K$ & 35 & +20 & $\begin{array}{l}\text { Vincristine } \\
\text { Lomustine }\end{array}$ & 8 & $\begin{array}{c}\text { Gliosarcoma, } \\
\text { fronto-parietal } \\
\text { region }\end{array}$ \\
\hline 14 & Salvati [26] (2003) & $40 / M$ & 30 & +15 & & 11 & $\begin{array}{c}\text { GBM, } \\
\text { parietal lobe }\end{array}$ \\
\hline 15 & Yang [34] (2005) & $5 / M$ & 36 & +20 & & 10 & $\begin{array}{c}\text { GBM, } \\
\text { cerebellum }\end{array}$ \\
\hline 16 & Hope [13] (2006) & $15 / M$ & 40 & +14 & & 23 & AA, cerebellum \\
\hline 17 & Gessi [10] (2008) & $7 / M$ & 20.8 & +39.8 & & 8 & GBM, cerebellum \\
\hline 18 & $\begin{array}{c}\text { Hamasaki [12] } \\
\text { (2010) }\end{array}$ & $5 / M$ & 20.8 & - & & 35 & $\begin{array}{c}\text { GBM, } \\
\text { cerebellum }\end{array}$ \\
\hline 19 & Kamide [14] (2010) & $5 / M$ & 15 & +39 & & 29 & $\begin{array}{l}\text { High grade glioma, } \\
\text { cerebellum }\end{array}$ \\
\hline 20 & Our case & 10/K & 35.07 & +18 & $\begin{array}{c}\text { Vincristine } \\
\text { Etoposide } \\
\text { Cyclofosfamide }\end{array}$ & 12 & $\begin{array}{c}\text { AA, } \\
\text { cerebellum }\end{array}$ \\
\hline
\end{tabular}

$M$ - male, F-female, GBM - glioblastoma multiforme, $A A$ - anaplastic astrocytoma

at the moment of diagnosis. The median time from irradiation to the occurrence of the secondary tumour was 8.75 years (range: 2.5 to 61 years) and was dependent neither on gender nor on age. There was also no difference in the latency period dependent on the irradiation dose and other methods of initial treatment. The authors noticed that in the case of neuraxis or whole brain irradiation, the latency period was shorter (median period of 7.1 years) comparing to local irradiation (median period of 10.2 years, $p=0.0350$ ). Glioblastoma was found in $75 \%$ of cases of secondary tumours and anaplastic astrocytoma was diagnosed in the other $25 \%$ of cases. Table II presents different treatment modalities. 
Median survival for the whole group was 11 months. Two-year overall survival was $13 \%$. For the group of 35 patients treated with radiation therapy (median total dose $50 \mathrm{~Gy}$, range from 30 to $76 \mathrm{~Gy}$ ), the median survival was 13 months and 2-year overall survival was $20.5 \%$, compared with 8 months and $3 \%$ for those who did not receive repeated irradiation. The difference in survival was statistically significant $(p=0.0009)$. Better prognosis was related to histology of anaplastic astrocytoma. Two-year overall survival was $30.3 \%$ for those diagnosed with anaplastic astrocytoma and $7.3 \%$ for patients diagnosed with glioblastoma $(p=0.0013)$. Acute toxicity of reirradiation was low. Episodes of brain oedema were treated with steroids, allowing completion of treatment. Serious late toxicity, e.g. brain radionecrosis, was seen in $2 \%$ of patients $[1,2,8,31]$. The data obtained suggest that reirradiation is the proper treatment option for patients diagnosed with RIMG. Neither surgery nor chemotherapy correlated with improvement in survival ( $p=0.164, p=0.536$, respectively).

\section{Conclusions}

According to the literature and our own experience, concurrent chemoradiation is an effective treatment method for RIMG, leading to results comparable to treatment of primary high-grade gliomas.

\section{Disclosure}

The authors report no conflict of interest.

\section{References}

1. Arcicasa M, Roncadin N, Bidoli E, Dedkov A, Gigante M, Trovo MG Reirradiation and lomustine in patients with relapsed highgrade gliomas. Int J Radiat Oncol Biol Phys 1999; 43: 789-793.

2. Bauman GS, Sneed PK, Wara WM, Stalpers LJ, Chang SM, Mcdermott MW, Gutin PH, Larson DA. Reirradiation of primary CNS tumors. Int J Radiat Oncol Biol Phys 1996; 36: 433-441.

3. Berrington de Gonzalez A, Gilbert E, Curtis R, Inskip P, Kleinerman R, Morton L, Rajnerman P, Little MP. Second solid cancers after radiation therapy: a systematic review of the epidemiologic studies of the radiation dose-response relationship. Int J Radiat Oncol Biol Phys 2013; 86: 224-233.

4. Cahan WG. Radiation- induced-sarcoma. 50 years later. Cancer 1998; 82: 6-7.

5. Cahan WG, Woodard HQ, Higinbotham NL, Stewart FW, Bradley LC. Sarcoma arising in irradiated bone: report of eleven cases. Cancer 1948; 1: 3-29.

6. Chowdhary A, Spence AM, Sales L, Rostomily RC, Rockhill JK, Silbergeld DL. Radiation associated tumors following therapeutic cranial radiation. Surg Neurol Int 2012; 3: 48-52.
Table II. Different treatment modalities for $92 \mathrm{pa}-$ tients diagnosed with RIMG [21]

\begin{tabular}{|l|c|}
\hline Treatment & $n$ \\
\hline SUR & $24(26.1 \%)$ \\
\hline SUR + CHEM & $13(14.1 \%)$ \\
\hline SUR + RT & $11(12 \%)$ \\
\hline RT + CHEM & $8(8.7 \%)$ \\
\hline RT & $8(8.7 \%)$ \\
\hline SUR + RT + CHEM & $8(8.7 \%)$ \\
\hline CHEM & $2(2.2 \%)$ \\
\hline Not treated & $18(19.5 \%)$ \\
\hline Total & $92(100 \%)$ \\
\hline
\end{tabular}

SUR - surgery, CHEM - chemotherapy, RT - radiotherapy

7. Cohen MS, Kushner MJ, Dell S. Frontal lobe astrocytoma following radiotherapy for medulloblastoma. Neurology 1981; 31: 616-619.

8. Combs SE, Gutwein S, Thilman C, Edler L, Debus J, SchulzErtner D. Reirradiation of recurrent WHO III grade astrocytomas using fractionated stereotactic radiotherapy (FSRT). Strahlenter Onkol 2005; 18: 768-773.

9. Furuta T, Sugiu K, Tamiya T, Matsumoto K, Ohmoto T. Malignant cerebellar astrocytoma developing 15 years after radiation therapy for a medulloblastoma. Clin Neurol Neurosurg 1998; 100: 56-59.

10. Gessi M, Maderna E, Guzzetti S, Cefalo G, Massimino M, Solero CL, Finocchiaro G, Pollo B. Radiation-induced glioblastoma in a medulloblastoma patient: a case report with molecular features. Neuropathology 2008; 28: 633-639.

11. Grabb PA, Kelly DR, Fulmer BB, Palmer C. Radiation-induced glioma of the spinal cord. Pediatr Neurosurg 1996; 25: 214-219.

12. Hamasaki K, Nakamura H, Ueda Y, Makino K, Kuratsu J. Radiation-induced glioblastoma occurring 35 years after radiation therapy for medulloblastoma: case report. Brain Tumor Pathol 2010; 27: 39-43.

13. Hope AJ, Mansur DB, Tu PH, Simpson JR. Metachronous secondary atypical meningioma and anaplastic astrocytoma after postoperative craniospinal irradiation for medulloblastoma. Childs Nerv Syst 2006; 22: 1201-1207.

14. Kamide T, Nakada M, Hayashi J, Suzuki T, Hayashi Y, Uchiyama N, Kijima T, Hamada J. Radiation induced cerebellar high-grade glioma accompanied by meningioma and cavernoma 29 years after the treatment of medulloblastoma: a case report. J Neurooncol 2010; 100: 299-303.

15. Klériga E, Sher JH, Nallainathan SK, Stein SC, Sacher M. Development of cerebellar malignant astrocytoma at site of a medulloblastoma treated 11 years earlier. Case report. J Neurosurg 1978; 49: 445-449.

16. Koksal Y, Toy H, Unal E, Baysal T, Esen H, Paksoy Y, Ustun ME. Pilocytic astrocytoma developing at the site of a previously treated medulloblastoma in a child. Childs Nerv Syst 2008; 24: 289-292.

17. Komatsu F, Kawaguchi H, Tsugu H. Oshiro S, Komatsu M, Fukushima T, Nabeshima K, Inoue T. Radiation-induced astrocy- 
toma with rapid malignant transformation: case report. Neurol Med Chir (Tokyo) 2011; 51: 243-246.

18. Malde R, Jalali R, Muzumdar D, Shet T, Kurkure P. Gliosarcoma occurring 8 years after treatment for a medulloblastoma. Childs Nerv Syst 2004; 20: 243-246.

19. Nakamizo A, Nishio B, Inamura T, Koga H, Yamabe A, Kuba H, Matsushima T, Fukui M. Evolution of malignant cerebellar astrocytoma at the site of a treated medulloblastoma: report of two cases. Acta Neurochir (Wien) 2001; 143: 697-700.

20. Osumi AK, Mclendon RE, Tien RD, Friedman HS, Graham M, Hockenberger B, Halperin EC, Oakes WJ. Well differentiated astrocytoma occurring nine years after radiation therapy for medulloblastoma. Clin Neuropathol 94; 13: 281-285.

21. Paulino AC, May WY, Chintagumpala M, Taher A, Teh BS. Radiation induced malignant gliomas: is there a role for reirradiation? Int J Radiat Oncol Biol Phys 2008; 71: 1381-1387.

22. Pearl GS, Mirra SS, Miles ML. Glioblastoma multiforme occurring 13 years after treatment of a medulloblastoma. Neurosurgery 1980; 5: 546-551.

23. Pettorini BL, Park YS, Caldarelli M, Massimi L, Tamburrini G, Di Rocco C. Radiation-induced brain tumors after central nervous system irradiation in childhood: a review. Childs Nerv Syst 2008; 24: 793-805

24. Safneck JR, Napier LB, Halliday WC. Malignant astrocytoma of the optic nerve in a child. Can J Neurol Sci 1992; 19: 498-503.

25. Salvati M, D'Elia A, Melone GA, Brogna C, Frati A, Raco A, Delchi R. Radio-induced gliomas: 20-year experience and critical review of the pathology. J Neurooncol 2008; 89: 169-177.

26. Salvati M, Frati A, Russo N, Caroli E, Polli FM, Minniti G, Delfini R. Radiation induced gliomas: report of 10 cases and review of the literature. Surg Neurol 2003; 60: 60-67.

27. Schmidbauer M, Budka H, Bruckner R, Vorkapic P. Glioblastoma developing at the site of a cerebellar medulloblastoma treated 6 years earlier. Case report. J Neurosurg 1987; 67: 915-918.

28. Scholtyssek F, Zwiener I, Schlamann A, Seidel C, Meixensbeger J, Bauer M, Hoffman KT, Combs SE, Bueren AO, Kortmann RD, Müller K. Reirradiation in progressive high-grade gliomas: outcome, role of concurrent chemotherapy, prognostic factors and validation of a new prognostic score with an independent patient cohort. Radiat Oncol 2013; 8: 161-169.

29. Strojan P, Popović M, Jereb B. Secondary intracranial meningiomas after high-dose cranial irradiation: report of five cases and review of the literature. Int I Radiat Oncol Biol Phys 2000; 48: 65-73.

30. Van Calenbergh F, D'Haen B, Dom R, Menten J, Plets C. Secondary supratentorial anaplastic astrocytoma following treatment of medulloblastoma. Eur J Paediatric Neurol 1999; 3: 177-180.

31. Veninga T, Langendijk HA, Slotman BJ, Rutten EH, van der Kogel AJ, Prick MJ, Keyser A, van der Maazen RW. Reirradiation of primary brain tumors: survival, clinical response and prognostic factors. Radiother Oncol 2001; 59: 127-137.

32. Vinchon M, Leblond P, Caron S, Delestret I, Baroncini M, Coche B. Radiation-induced tumors in children irradiated for brain tumor: a longitudinal study. Childs Nerv Syst 2011; 27: 445-453.

33. Xu XG, Bednarz B, Paganetti H. A review of dosimetry studies on external-beam radiation treatment with respect to second cancer induction. Phys Med Biol 2008; 53: 193-241.
34. Yang SY, Wang KC, Cho BK, Kim YY, Lim SY, Park SH. Radiation-induced cerebellar glioblastoma at the site of a treated medulloblastoma. J Neurosurg Pediatrics 2005; 102: 417-422.

35. You SH, Lyu CJ, Kim DS, Suh CO. Second primary brain tumors following cranial irradiation for pediatric solid brain tumors. Childs Nerv Syst 2013; 29: 1865-1870. 